\title{
ICT services features to support intrinsic value activities for productive ageing
}

\author{
Norisan Abd Karim, Haryani Haron, Wan Adilah Wan Adnan \\ Faculty of Computer and Mathematical Sciences, Universiti Teknologi MARA, Malaysia
}

\begin{tabular}{l}
\hline \hline Article Info \\
\hline Article history: \\
Received Jun 5, 2019 \\
Revised Aug 9, 2019 \\
Accepted Aug 26, 2019 \\
\hline
\end{tabular}

\section{Keywords:}

ICT services features Intrinsic value activities Productive ageing

\begin{abstract}
Intrinsic values associated with ICT services activities in productive ageing. Given the advances made in ICT services that have been widely used, elderlies need to be equipped with the knowledge in using the services. The lack of ICT usage among elderlies is because of the low motivation to use the ICT applications. This in turn could be due to the lack of intrinsic values associated with the use of ICT applications among elderlies. This study explores further the features of ICT services needed to support intrinsic values activities. Brainstorming sessions is conducted in this study where it involved six ICT experts in order to identify ICT services features to support intrinsic value activities. Intrinsic motivation features are significant features in ICT services to support intrinsic value activities for productive ageing. There are five intrinsic motivation features identified in this research, which are autonomy, competence, relatedness, altruism and curiosity. The ICT services to support intrinsic value activities model comprises of the ICT services characteristics that are transactive, community-based with online communication channels, and incorporated with intelligent agents.
\end{abstract}

Copyright $(0) 2020$ Institute of Advanced Engineering and Science. All rights reserved.

\section{Corresponding Author:}

Norisan Abd Karim,

Faculty of Computer and Mathematical Sciences,

Universiti Teknologi MARA Shah Alam, Selangor

Email: norisan@tmsk.uitm.edu.my

\section{INTRODUCTION}

The world is confronted with trends in the increasing population of elderlies, and the fast development of ICT services in human daily lives that lead to the increasing number of elderlies ICT users in the future [1]. Thus, the characteristics of the ICT services for future needs of elderlies need to be duly identified to cater to their ever increasing and complex needs and demands.

Even though ICT can play an important role in productive aging, the current ICT activities for elderlies are still lacking in terms of attracting them to use the technology [2, 3]. ICT features for productive aging in Malaysia are unfamiliar and still at its infancy stage. Most of the prior researchers focus more on ICT that are related to assistive technologies, which are related in physical productivities that help elderlies in daily activities.

Little research has been undertaken in social-related technologies as key enablers used to increase self-actualization, self-esteem and give more autonomy to the elderlies. A large number of past researchers focussed on the technology which fulfilled the first three levels of human needs based on Maslow's hierarchy of needs, which are physiological (such as air, water, food, shelter etc.), safety (such as personal security, employment, health etc.), and love and belonging (such as friendship, intimacy, family etc.). Others in the hierarchy include self-esteem and self-actualization. Prior studies look into technologies that were related to health [4] (survival and safety) [5-7] and aging at home [8]. However, ICT services which enhance the social relatedness, self-development, self-esteem and self-actualization leading to intrinsic values among the elderlies appear to be lacking. Elderlies are motivated to use ICT services if they think the services can give 
them the much needed intrinsic values. Whilst ICT services have the capability of providing social inclusiveness, its features should also be able to support the intrinsic value activities for elderlies. Generally speaking, intrinsic values emerged from the activities motivated by intrinsic motivation. In order to provide a certain quality of life to the elderlies, there is a need for intrinsic values elements in their activities. This research will highlight the productive ageing activities that exhibit intrinsic values. According to past researchers, the productive ageing activities are divided into four types. These are market activities, caregiving, volunteering [9-15] and self-development [9, 13, 15].

Intrinsic motivations are among the contributing factors to promote participation in people activities [16,17]. Intrinsic motivation is defined as performing the action or activity because of inherently rewarding pursuits or intrinsic values [18]. Coon and Miterer [19], defined intrinsic motivation as: "Intrinsic motivation occurs when we act without any obvious external rewards. We simply enjoy an activity or see it as an opportunity to explore, learn, and actualize our potentials". Basically, activities motivated by intrinsic motivation are rewarding intrinsic values [20]. ICT has good potentials to promote social activities among elderlies [21]. They will engage in ICT-related activities if they find it fun and enjoyable, and suit their needs [17]. Intrinsic motivation features are significant features in ICT services to support intrinsic value activities for productive ageing. Thus, this paper present ICT services features for the elderly activities that associates with intrinsic motivations for productive ageing.

\section{RESEARCH METHOD}

Research that provides understanding of people's experience, behaviors, interactions and social context uses qualitative research [22]. Past researchers [23-26] used qualitative research method in their works where its' involved with people experience and make interpretation to come out with the opinion. Thus, qualitative research method is applied in this study. The process of ICT services features identification involves the selection of experts, brainstorming sessions and identification of ICT services features.

The selection of experts from specific backgrounds in this study is categorized under the focus group approach. The process of identification and validation of the technologies involved face-to-face approach that provided complex data, which in turn involved deep explanations and simultaneous feedback from the experts themselves. Since this study focuses on ICT services field only, a six-member expert panel were employed to participate in this research to get the knowledge and experience related to the defined topic. Besides the experts being good in ICT, some of them have been involved in a number of projects involving elderlies. The experts are experienced in providing ICT services solutions, thus this made the work in identifying ICT services features much easier. Brainstorming sessions were held to identify what are the suggested ICT services to support intrinsic values activities for productive ageing. Various scenarios of elderlies' activities and current ICT services used by the elderlies were given to the experts so that they could get a deeper understanding of the current situation. The scenarios described the concept of productive ageing activities and the various motivations that attracted the elderlies to engage in activities. The current ICT services used by the elderlies were also described in the scenarios, as it will help the experts think of suitable ICT services for the elderlies in the future. Every expert gave feedback regarding this matter. The experts described in detail how the features of ICT services supported intrinsic motivations, which were associated with intrinsic values activities for productive ageing.

After the experts have completed the brainstorming sessions by identifying the ICT services for the elderlies, examples of ICT services identified by them were compared between the experts. Lastly, the agreed ICT services with the supporting comments were provided to justify the identification of ICT services for the elderlies.

\section{DATA ANALYSIS AND RESULT}

The group of experts was involved in identifying ICT services features to support intrinsic value activities for productive ageing. The experts were given the elderlies' current scenarios, which described the activities of the elderlies and the familiar ICT services that have been used by the elderlies. They looked into the ICT services for elderlies and related them to intrinsic motivations theories that could encourage the participation of elderlies in the intrinsic value activities.

\subsection{ICT Services in Volunteering}

All the experts involved in this study agreed that the ICT services that they have suggested supported intrinsic motivations. They strongly emphasized the ICT services and platforms that have been identified for productive ageing such as social media that supported collaborative communication supported competence intrinsic motivation where the ICT services provided information to others. Competence refers 
to the people's abilities to solve problems where it is concerned with the importance of knowledge and skills. The following quotation explained by the experts how ICT services in volunteering are able to support competence intrinsic motivation.

"Elderlies can exemplify positive values, ideas and beliefs. It would allow the elderlies to be able to share their knowledge, opinion and experience either in a one-to-one session or in group sessions. The elderlies could also participate as experts, trainers or advisors to people through online learning platforms or advisory systems, virtual learning network (VLN) or teleconference. They also could contribute and lead any group, society or committee in whatever they can do."

Secondly, the quotation below shows that, experts agreed that the ICT services and platforms that have identified which were related to volunteering supported autonomy intrinsic motivations. Autonomous is where people are able to govern their own activities. They believed that the autonomy feature was needed, as it would encourage productive ageing.

"The ICT services that have been identified were able to support information where it could provide choices of input in the activities. Technology such as web portal also could have sub domain of activities where the user would be free to participate according to their choice. With Internet technologies, elderlies were free to interact with others at their comfort of time and place. The Internet technologies supported various ways to exhibit skills and knowledge. For example, by using advance FB that offered better features, people could provide their expertise through comments, interactive video conferencing, wall, blog link and others. FB could have many channels for the users to choose for the activities and they are more interactive. Collaborative technologies could support elderlies to explore and establish network with various suitable individuals, groups and community such as webinar, online portal, and online crowdsourcing.

Online portal or Apps that provided elderlies real-time information concerning all matters relating to volunteer work were examples of ICT services that support autonomy intrinsic motivation. It would make it easier for the elderlies to be able to choose and involve themselves in voluntary work as a committee where they could choose what they wanted to be and a lot of information was available online in the system".

Relatedness is another intrinsic motivation in technologies that is related to volunteering activities. Relatedness is when the interaction or connection exists in the activities to establish the relationship between human. Experts explained how ICT services are able to support intrinsic motivation in elderlies' productivity in the following excerpt.

"ICT services in volunteering allowed elderlies to exchange information, experiences and opinion with others. ICT platforms such as web portals, interactive channels and others provided online communities for the elderlies to join and participate and it would create alliance in their fields of interest. ICT services such as e-Learning, social media and others provided support to family and friends in terms of financial, time, and effort by giving valuable input such as skills and knowledge through online groups (WhatsApp with more interactivity, interactive volunteering online portal etc.). The network platform provided the portal and software as well as the procedural and legal support to the elderlies in providing their expertise. They have a wealth of skills and lifetime of experiences that are valuable to the community that could be delivered through interactions. The ICT services identified also would allow elderlies to be involved in the larger group for the purpose of contributing to the society".

In the volunteering activities, experts found that altruism intrinsic motivation through ICT services encourage productive ageing. Altruism is described as being very helpful. The ICT services identified provided the platforms for elderlies to help other people in many other ways.

"The ICT services provided information online in areas needed by the organization, community, groups and others. The elderlies were able to provide comments to videos / messages posted to any online eforum/group, blog, Wikipedia etc... More interactivity could be expected from the technology in the future. The elderlies were able to help others by providing their expertise in areas needed by any group through online platforms to organizations, communities etc.. They could participate as a member or committee in any specialized online group such as charity and donation groups. Internet banking applications were very useful where elderlies could easily participate in online donation and "waqaf" programs".

From the views of all the experts, they showed that ICT services with advance social media, web / mobile technologies that supported collaborative communications such as crowdsourcing, e-learning were the technologies used to support intrinsic motivation for volunteering activities. In addition, experts also highlighted the importance of interactivity elements in information technology.

\subsection{ICT Services in Care-Giving}

All experts agreed that competence, autonomy, relatedness and altruism intrinsic motivations were needed in the ICT services to promote productive ageing. The following quotation shows how ICT services in care-giving are able to support competence intrinsic motivation features. 
"The suggested ICT services in caregiving would allow elderlies to exhibit their competencies where they would be able to join groups, contribute and lead knowledge and experience in any parenting groups. They could use caregiving applications using smart phones, smart homes or CCTVs to download lessons and share with others any unusual negative activities. Elderlies could use the technology, which can assist them in monitoring members of their households and to highlight to them when there are any matters such as health or physical issues with the individuals. Social media with the advance in video conferencing would be very good platforms for parenting advices that could help younger generation seek guidance. The elderlies would be able to use the smart home technology for the good of the whole household. All activities in the house could be monitored anywhere.".

In addition, they could also provide knowledge to software developers on integrated smart homes as part of the development of these solutions by being part of the design team, and by providing ongoing feedback as the services utilized. All the experts recognized that ICT services with autonomy intrinsic motivation features were needed in the ICT services to promote productive ageing as contained in the following excerpt.

"ICT services identified for caregiving activities support autonomy intrinsic motivations where these technologies provide support for domestic work through available technologies for example vacuum cleaner robots, smart home applications and others alike. The technologies would simplify their lives tremendously and reduce the time required for the work. The elderlies would also be free to choose the activities related to parenting or domestic work such as they could use Web 4.0 or Mobile Commerce that would allow users to buy groceries online. Social Media, e-forums would enable to support or explore and establish networks with various suitable parenting groups".

Experts also agreed that relatedness intrinsic motivations supported by identified ICT services in caregiving activities where the main requirement for the ICT would enable them to interact with one another in real-time and visually as explained in the following excerpt.

"The identified ICT services such as social media could provide support in terms of advice, communication through Skype and others alike that have inspired younger generation to make wiser decisions. The technology would assist elderlies and the younger generation to take care of each other more effectively and efficiently. The elderlies also could use outsourcing services offered through online to complete domestic works and others. Elderlies can get house cleaners or house cleaning services through online applications. This smart technology would allow individuals to support one another via their interconnected homes, which could also be connected to each other's homes. This facility would allow individuals to actively communicate with each other".

Lastly, the experts agreed that ICT services that have been suggested for caregiving could support altruism intrinsic motivations in productive ageing. Experts justified how ICT functions could provide the relevant intrinsic motivations for elderlies in the following excerpt.

"The technology such as mobile commerce, social media, online banking, robots, smart homes, CCTVs would give opportunities to the elderlies to lend a helping hand to others. Social media is one of the ways to provide support in terms of advice, communication thorough Skype and others. Elderlies would be able to transfer money online as needed to close family. The technology would and could enhance the parenting capabilities at all times and provide wider coverage with the help of ICT services platforms that would support and provide more interactivity to the elderlies".

From the data shared, it could be concluded that all experts agreed that ICT services such as social media, web/mobile technologies and assistive technologies such as robotic or artificial intelligence applications are very helpful to the elderlies in caregiving activities. Assistive technology makes available several types of services and devices designed to help people with disabilities function within their environment.

\subsection{ICT Services in Self-Development}

For self-development activities, all experts agreed that the identified ICT services supported competence, autonomy, relatedness and curiosity intrinsic motivations. Experts emphasized how competence intrinsic motivation that has been applied in ICT could help elderlies in self-development activities.

"Technologies such as social media with advance video conferencing, web technologies that allowed collaborative learning would support elderlies in their effort to improve their knowledge while providing information. They could also provide expertise in areas needed by the organization or committees in which they participated. For example, while these technologies provided expertise, it would better their personalities via good feedback. Elderlies would be able to take up the challenges of new activities that suited their physical and mental capabilities. They would be able to learn new knowledge through new technologies. Smart applications such as the Integrated Smart Assistant with the Elderlies would be very 
helpful for the them where these smart applications help build individual knowledge by allowing customized contents to be recommended to the elderlies based on their individual profiles".

Experts emphasized that identified ICT services would support autonomy intrinsic motivation in self-development activities as elderlies have a choice in getting new knowledge.

"For example, Internet technologies provide various web sites, blogs and learning applications. Elderlies could experience and enjoy their spiritual programs from the comfort of their homes. New technologies such as VR and augmented reality allow for self-learning skills. Elderlies could also explore opportunities and find support that could help and enable self-care capabilities, for example, health care tips through online support groups".

Experts said that the purpose of ICT services is to connect one party with another. However, the way of communication changes from time to time made connectivity challenging. The elderlies wanted to participate in self-development because of they were looking for affiliations. Relatedness makes them active in the activities. Experts explained that the relationship between the identified ICT services and relatedness features as follows:

"Elderlies could get more friends when they get themselves involved with self-development activities such as online learning community groups, Facebook, webinar, blog and others. These ICT services provide communication and knowledge via online group that enabled elderlies to communicate with others. They could build up specific pillars for self-development such as for religious activity. The smart assistance would allow elderlies to access the information real-time anywhere, at any time and at same time, they are able to participate. The interactive network technology such as Interactive TV could be a platform to gain knowledge where the elderlies could ask questions on the TV screen. They also could ask questions in real time through U-tube applications. New ICT services allow strengthening the relationships between families and friends. Artificial Intelligence Health applications could help users and close families to keep track of the physical conditions of elderlies, thus enable faster communication and actions to be taken. ICT services and intelligence systems would educate elderlies on how to live more sustainably".

As mentioned in previous findings, elderlies are motivated to participate in activities because of their curiosities. Experts have identified ICT services that could help elderlies fulfill their curiosities.

"ICT services such as teleconferencing, interactive wiki, e-learning, social media and others could help elderlies seek new findings, knowledge and skills. The content available on the Internet such as e-forum for the elderlies help users acquires better understanding of their needs. ICT services such as online learning provide hands-on experience to elderlies anywhere and anytime. It would provide a better learning experience especially for knowledge area that is experiential in nature. It clearly shows that ICT services such as playing games and doing puzzles that keep the elderlies busy will help keep their brains active. The elderlies are interested to participate in recreational and exercise tools because the new Artificial Intelligence technology will assist the elderlies in understanding their health condition and recommend suitable self-care development activities. It could also provide various recommendations on personal selfcare development in line with individual learning capabilities and experience. The elderlies would also be able to explore new ways to monitor and track health conditions by using technology".

Lastly, it can be summarized that all experts acknowledged social media, web technologies that support collaborative communications, all kinds of interactive channels of communications and artificial intelligence applications deemed to be a very good platforms of ICT services for elderlies to improve themselves for a better quality of life.

\subsection{Summary of ICT Services in Supporting Intrinsic Motivations}

From the views gathered from all the experts in this study, it shows that competence, autonomy, relatedness, curiosity and altruism intrinsic motivation are important features in ICT services as these elements or dimensions could help increase participation of the elderlies in the activities. Table 1 summarizes the suitable ICT services for the elderlies as identified by the experts as motivation theory is used to increase elderlies' participation in the activities.

Based on the previous data analysis from the prior articles [27, 28] and considering opinions from the experts, it shows that the expected ICT services characteristics model comprises of the ICT services characteristics. These characteristics are transactive in nature, community-based with online communication channels, and incorporated with intelligent agents. The expected needs, which must be included in the activities of the elderlies, are philanthropy, interrelationship and lifelong learning. Based on the data gathered, it shows that elderlies are looking forward to engage in philanthropy activities that are supported by ICT community-based services. The intrinsic motivation features such altruism, competence, autonomy and relatedness should be supported by ICT services as platforms for philanthropy activities. They expect good values such as gratification or affiliation from the activities they participated. 
Table 1. The Intrinsic Motivation Features and ICT Services for Productive Ageing

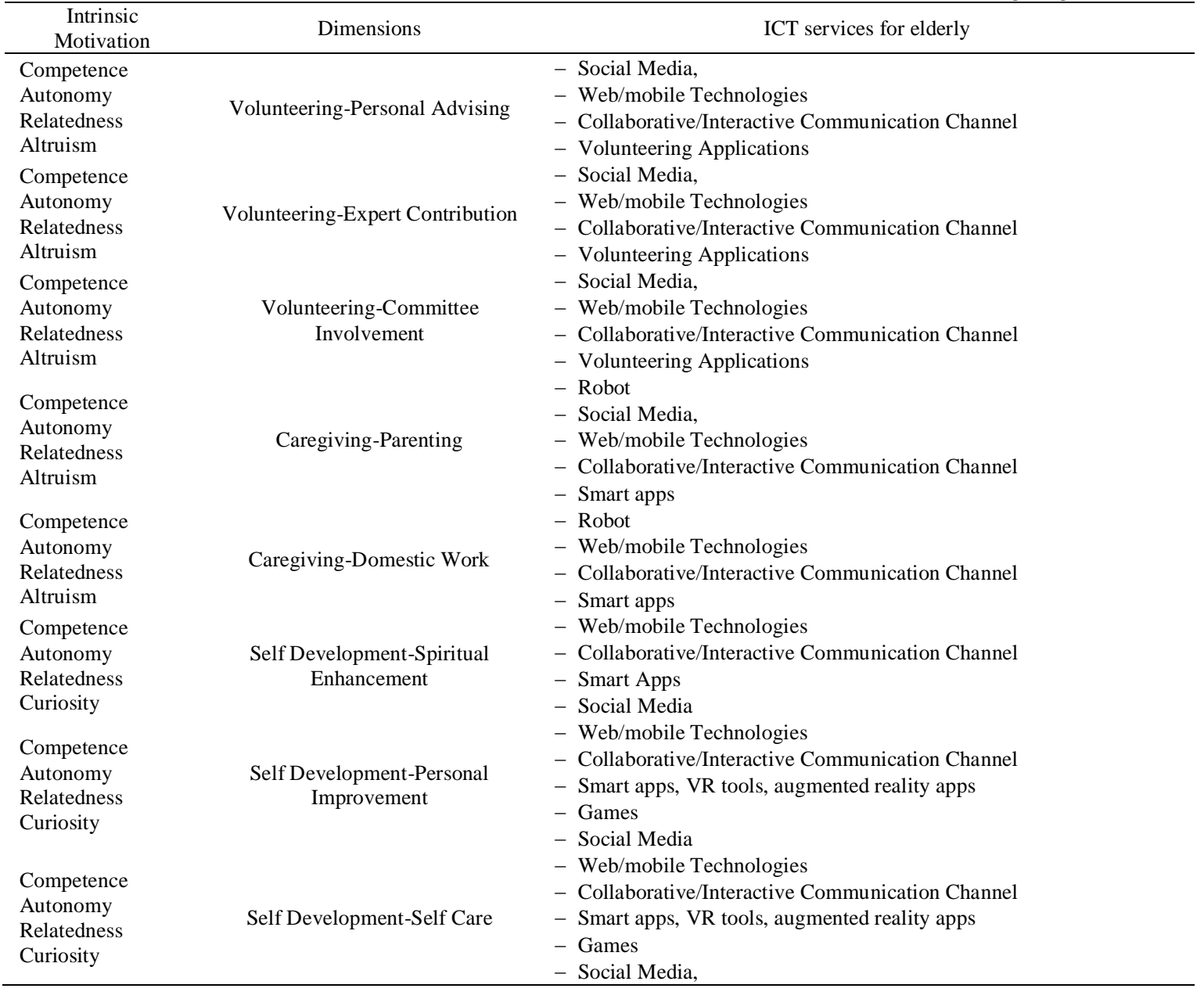

Elderlies also need the activities that allow for interrelationships supported by ICT, which in turn are supported by the community that is incorporated by intelligent agents. They want to have activities that provide knowledge sharing with others since they have valuable experience to share and guide other people. Intelligent agents such as smart monitoring systems for health and safety are important for interrelationship activities. The intrinsic motivations feature such as altruism, competence, autonomy and relatedness should be supported by ICT services as platforms for interrelationship activities. Elderlies expect intrinsic values such as gratification and affiliation in interrelationship activities.

Table 2. Synthesized of Intrinsic Motivations Needs and Expected ICT Services

\begin{tabular}{|c|c|c|c|}
\hline $\begin{array}{c}\text { Intrinsic } \\
\text { motivation }\end{array}$ & $\begin{array}{l}\text { Expected Needs (Intrinsic } \\
\text { Based activities) }\end{array}$ & The Main Expected ICT Services Characteristic & $\begin{array}{l}\text { Intrinsic } \\
\text { Value }\end{array}$ \\
\hline $\begin{array}{l}\text { Altruism } \\
\text { Competence } \\
\text { Autonomy } \\
\text { Relatedness } \\
\text { Altruism }\end{array}$ & $\begin{array}{l}\text { Philanthropy } \\
\text { (caregiving/volunteering) }\end{array}$ & Community Based with online communication channel & $\begin{array}{l}\text { Gratification, } \\
\text { Affiliation }\end{array}$ \\
\hline $\begin{array}{l}\text { Competence } \\
\text { Autonomy } \\
\text { Relatedness }\end{array}$ & $\begin{array}{l}\text { Interrelationship } \\
\text { (caregiving/volunteering) }\end{array}$ & $\begin{array}{l}\text { Community Based with online communication channel } \\
\text { Intelligent agents }\end{array}$ & $\begin{array}{l}\text { Gratification, } \\
\text { Affiliation }\end{array}$ \\
\hline $\begin{array}{l}\text { Competence } \\
\text { Autonomy } \\
\text { Relatedness } \\
\text { Curiosity }\end{array}$ & $\begin{array}{l}\text { Life long learning } \\
\text { (self-development) }\end{array}$ & $\begin{array}{l}\text { Community Based with online communication channel } \\
\text { Intelligent agents } \\
\text { Transactive Nature }\end{array}$ & Self-Esteem \\
\hline
\end{tabular}

Intelligent agents also seem to be important ICT services characteristics of the future especially in lifelong learning activities. The ICT services should allow for competence, autonomy, relatedness and 
curiosity intrinsic motivations in lifelong learning activities. Community-based activities incorporated with intelligent agents that are transactive in nature are expected to help elderlies in their learning process such as provide hands on experience and recommend suitable levels of modules according to users' knowledge. These activities will help to improve the quality of life and increase self-esteem of the elderlies. Table 2 shows synthesized of Intrinsic motivations needs and expected ICT services.

\section{CONCLUSION}

From the data that have been collected in this case study, five intrinsic motivations that promote productive ageing were identified. This study found that elderly are performing activities in socializing, self-development, and care-giving activities [27]. These activities are motivated by intrinsic motivations, which consist of autonomy, competence, relatedness, curiosity and altruism [28]. All the elderly in this study preferred to involve in activities towards non-monetary returns, which were intrinsically rewarding. However, since this study is qualitative study, the results of the study are not conclusive and cannot be used for generalization. The findings are used for understanding of productive aging in the context of Malaysia. Thus these findings can be used for further decision-making. A prior researcher [17] found that intrinsic motivations could be incorporated into ICT services design. Thus, it is believed that these five intrinsic motivational features will be useful in helping to incorporate in the ICT services for the elderly in particular. To continue promoting productive ageing, attention should be paid to the elderly who are still capable in contributing their services or for those who want to remain engage in the community regardless to their weaknesses with help of Information Technology capability. The features that are related to intrinsic motivation enables giving advice, commenting on the issues, clarifying things, making decisions and managing things, supporting knowledge and skills, investigating, generating ideas, and helping others. These intrinsic motivation features that attract elderly to participate in activities should be considered in Information, Communication and Technology.

With the help of ICT services supported by intrinsic motivation theories, the elderly are able to keep productive in their daily activities. Experts conclude that, the expected ICT services characteristics model comprises of the ICT services characteristics which are transactive in nature, community-based with online communication channels, and incorporated with intelligent agents. They prefer the activities that related to philanthropy, interrelationship and life-long learning. All experts in this study agreed that, communication channel such as social media with interactive features help the elderly to perform their activities in effective and efficient ways.

Experts also highlighted web technologies that support collaborative communication as this technology such as e-learning, webinar and others will give the opportunities to the elderly to share their knowledge, skills and self-development purposes. This is in line with the prior researchers work that investigated on how of web technologies helps elderly in their daily activities [28]. The elderly also needs assistive technologies with multifunction, as it will make their daily work such as house chores easier.

\section{ACKNOWLEDGEMENTS}

The authors would like to thank to the Research Management Institute, Universiti Teknologi MARA for the research support, their valuable support and input to this research.

\section{REFERENCES}

[1] H. Bjering, J.Curry \& A. Maeder. Gerontechnology: "The importance of user participation in ICT development for older adults", Studies in Health Technology and Informatics, 204, 7-12, 2014.

[2] Abdul Malik, S., Azudin, M., Abdullah, L. M., Mahmud, M., " Older people and their use of mobile devices: Issues, purpose and context”, Technology for the Muslim World, ICT4M 20142014 the 5th International Conference on Information and Co, (2014a).

[3] Abdul Malik, S., Azudin, M., Abdullah, L. M., Mahmud, M., "An Investigation on the Use of Mobile Devices Among Older People. Advanced Science Letters", 21(10), (2015b, November 10).

[4] Suzuki, T., Jose, Y., \& Nakauchi, Y. "Based on Intelligent Environment Technologies”, 3207-3212, 2011.

[5] Ahrary, A., Yang, W., Inada, M., Nakamatsu, K., "Development of the Lift Assist Chair for the Elderly People "Rakutateru",", Procedia Computer Science 131, 31-37, 2018.

[6] Arshad, A., Khan, S., Z. Alam, A. H. M., Ismail, A. F., \& Tasnim, R., "Capacitive proximity floor sensingsystem for elderly tracking and fall detection”, IEEE 4th International Conference on Smart Instrumentation, Measurement and Application (ICSIMA), 1-5. 2017. 
[7] Portet, F., Vacher, M., Golanski, C., Roux, C., \& Meillon, B., "Design and evaluation of a smart home voice interface for the elderly: acceptability and objection aspects", Personal and Ubiquitous Computing, 17(1), 127-144, 2011.

[8] Zhu, C., Oda, M., Luo, X., Watanabe, H., \& Yan, Y., "Platform development of an omnidirectional mobile robot for the elderly's walking support and the caregiver's power assistance”, 2009 IEEE International Conference on Robotics and Biomimetics (ROBIO), 1900-1905, 2009.

[9] Butler, R.N. (2010). “The 8 Proven Keys to a Long, Healthy Life. In The Longevity Prescription ”. New York.

[10] Reilly, P. O \& Caro, F. G., "An Overview of Literature. Productive Aging”, 37-41, 2013.

[11] Morrow-Howell, N., Hinterlong, J., \& Sherraden, M. (eds.)., "Advancing Research on Productivity in Later Life, Productive Aging. Concepts and Challenges", 2011.

[12] Sherraden, M., Morrow-Howell, N., "Productive aging: theoretical choices and directions", In: Morrow-Howell, N., Hinterlong, J., Sherraden, M. (eds.) Productive Aging: Concepts and Challenges. The John Hopkins University Press, Baltimore (2001).

[13] Peng, D., \& Fei, W., "Productive Ageing in China: Development of Concepts and Policy", 55(1), 121-139, 2013.

[14] Morrow-Howell, N., \& Wang, Y,." Productive engagement of older adults: elements of a cross-cultural research agenda". Ageing Int, 38, 159-170, 2013.

[15] Kim, J. P., "Productive aging of the elderly in Japan*”. Korean Soc. Sci. J, 1(1); 1-26, 2010.

[16] Giesbrecht, T., Pfister, J., \& Schwabe, G., "A Self-Determination Perspective on IT-based Citizen Advisory Support", 45th Hawaii International Conference on System Sciences, 2012.

[17] Goldhaber,T., "Using Theories of Intrinsic Motivation to Support ICT Learning for the Ageing Population"Springer, London. 359-362, 2012.

[18] Brown, L. V., "Psycology of Motivation", New York: Nova Science Publisher, 2007.

[19] Coon, D. \& Miltter, J. O., "Introduction to psychology: Gateways to mind and behavior with concept maps", Belmont, CA: Wadsworth, 2010.

[20] Holmes, T., Blackmore, E., Hawkins, R., \& Wakeford, T., "The Common Cause Handbook. In A Guide to Values and Frames for Campaigners, Community Organisers, Civil Servants, Fundraisers, Educators, Social Entrepreneurs, Activists, Funders, Politicians, and Everyone in Between", Public Interest Research Centre Ltd, 2012.

[21] Achilleos, A.P., Mettouris, C., Papadopoulos, G.A., Neureiter, K., Rappold, C., Moser, C., Tscheligi, M., Vajda, L., Tóth, A., Hanák, P., Jimenez, O., Smit, R., "The connected vitality system: Developing aneffective social presence system for older adults", 12th International Conference on Telecommunications. Crotia. 199-206, 2013.

[22] Evans, D. "Database searches for qualitative research", Journal of the Medical Library Association, 90, 290-293, 2002.

[23] Majid R.A., Noor N.L.M., Adnan W.A.W., “An Assessment Tool for Measuring Human Centered Design Adoption in Software Development Process", In: Rocha Á., Adeli H., Reis L., Costanzo S. (eds) Trends and Advances in Information Systems and Technologies. WorldCIST'18 2018. Advances in Intelligent Systems and Computing, vol 746. Springer, Cham, 2018.

[24] Salleh, S.S., Arshad, N. H., Aris, S.R.S, Janom, N., Mastuki, N., "Formulating Cohesive Digital Ecosystem of Micro Sourcing Business Process in Malaysia". Science and Information Conference (SAI), October, London, pp. 321-327.2013.

[25] J. Jasmis, S.Elias, A. Aziz et al., "Verification and validation of IM-DeCRuD approach using DESMET for its applicability", Indonesian Journal of Electrical Engineering and Computer Science. 13. pp1311 1317, 2019.

[26] Aziz NHN, Haron H, Harun AF, "Components of participatory engagement wthin E-learning community", Indonesian Journal of Electrical Engineering and Computer Science. 12. pp556-561, 2018.

[27] Karim N.A., Haron H., Adnan W.A.W., Abdullah N., "Dimensions for Productive Ageing", In: Saeed F., Gazem N., Patnaik S., Saed Balaid A., Mohammed F. (eds) Recent Trends in Information and Communication Technology. IRICT 2017. Lecture Notes on Data Engineering and Communications Technologies, vol 5. Springer, Cham.2018.

[28] Karim N.A., Haron H., Adnan W.A.W., Abdullah N. \& Mustafa S.M.S., "Intrinsic motivations for productive ageing". Indonesian Journal of Electrical Engineering and Computer Science. 13. 1228-1236. 10.11591/ijeecs.v13.i3.pp1228-1236, 2019. 